\title{
ANÁLISE DA EFICIÊNCIA NA GERAÇÃO DE RESÍDUOS NOS TERMINAIS PORTUÁRIOS DE CARGA GERAL UTILIZANDO DEA
}

\author{
B.T.G. Garcia ${ }^{1}$; M.A.V. da Silva ${ }^{1}$ e M.A.V. de Freitas ${ }^{2}$ \\ 1 Programa de Engenharia de Transportes - COPPE, Universidade Federal do Rio de Janeiro, 21941-914, Rio de \\ Janeiro-RJ, Brasil \\ 2 Programa de Planejamento Energético - COPPE, Universidade Federal do Rio de Janeiro, 21941-914, Rio de \\ Janeiro-RJ, Brasil \\ *breno.garcia@pet.coppe.ufrj.br
}

\section{RESUMO}

A partir da Política Nacional de Resíduos Sólidos, o setor portuário brasileiro foi obrigado a gerenciar os resíduos gerados nos portos e terminais portuários. A partir do inventário de resíduos foi possível analisar a eficiência na geração de resíduos nos terminais portuários que movimentam, predominantemente, a carga geral, utilizando o método de Análise Envoltória de Dados (DEA). O modelo DEA BCC orientado a output foi adotado. Além disto, este trabalho utilizou três análises, sendo, uma geral e duas par-a-par. O resultado da análise geral, em que considerou as três variáveis, apresentou oito terminais eficientes, tendo um terminal falso-eficiente. A
DMU 18 foi a mais eficiente, pois, obteve o maior valor na Composta Normalizada. Nas análises par-a-par, a fronteira eficiente foi formada por apenas duas DMU's, onde a presença da DMU 21 é observada nas três análises. Além disto, numa das análises par-a-par observou-se que o modelo atribuiu o maior valor na Composta Normalizada para a DMU 20 que não foi eficiente. Neste caso, os indicadores da Composta e Composta Normalizada foram desconsiderados da análise, utilizando os indicadores de eficiência padrão e invertida. Este artigo inclui a identificação dos terminais com as melhores e piores práticas gerenciais.

\section{ANALYSIS OF EFFICIENCY IN THE GENERATION OF WASTE IN GENERAL CARGO PORT TERMINALS USING DEA}

\begin{abstract}
Based on the National Solid Waste Policy, the Brazilian port sector was forced to manage the waste generated in ports and port terminals. From the inventory of waste, it was possible to analyze the efficiency in the generation of waste in port terminals that predominantly handle the general cargo, using the Data Envelopment Analysis (DEA) method. The output-oriented DEA BCC model was adopted. In addition, this work used three analyzes, one general and two peer-to-peer. The result of the general analysis, in which the three variables were considered, presented eight efficient terminals, having one false-efficient terminal. The DMU 18 was the most
\end{abstract}

efficient because it obtained the highest value in the Normalized Compound. In the peer-to-peer analysis, the efficient border was formed by only two DMU's, where the presence of DMU 21 is observed in the three analyzes. Moreover, in one of the peer-to-peer analyzes it was observed that the model attributed the highest value in the Normalized Compound to the DMU 20 that was not efficient. In this case, the composite and normalized composite indicators were disregarded from the analysis, using standard and inverted efficiency indicators. This article includes the identification of the terminals with the best and worst management practices.

KEYWORDS: Data Envelopment Analysis (DEA); Solid Waste; Port Terminal. 


\section{INTRODUÇÃO}

O setor portuário é o principal responsável pela entrada e saída de produtos de uma nação. Com a globalização, os portos tornaram-se os principais elementos do sistema logístico em atender às demandas dos mercados internacionais dada a possibilidade de movimentar quantidades significativas de cargas mundo afora. (Guedes et al., 2008; Monié e Vidal, 2006).

Com isso, é possível afirmar a importância do setor portuário no desenvolvimento das economias, locais e/ou de uma nação. Entretanto, há diversos problemas gerados pelas atividades portuárias, como por exemplo, a poluição do ar gerado pela movimentação de navios, caminhões e entre outros, diversos tipos de resíduos gerados pelos navios - resíduo orgânico, resíduos oleosos, entre outros (Bertoloto e Mello, 2011; Mohee et al., 2012).

No Brasil, o Poder Legislativo sancionou na forma da lei $\mathrm{n}^{\mathrm{o}} 12.305 / 2010$, a Política Nacional de Resíduos Sólidos (PNRS) que visa solucionar os diversos problemas ambientais, sociais e econômicos decorrentes do manejo inadequado dos resíduos sólidos. (Brasil, 2010). Para isto, a PNRS institui a responsabilidade compartilhada dos geradores de resíduos: fabricantes, importadores, distribuidores, comerciantes, entre outros (Brasil, 2010).

A nova legislação obriga o setor portuário a adotar medidas que visem um sistema eficiente de gestão integrado de resíduos. Para isto, é necessário identificar as fontes geradoras de resíduos, assim como a tipologia e o quantitativo de resíduos gerados (Brasil, 2010).

A partir disto, o problema de pesquisa neste artigo é: de que forma é possível analisar a eficiência na geração de resíduos nos terminais portuários brasileiros? Para buscar responder o problema de pesquisa apresentado, este trabalho possui o seguinte objetivo geral: analisar a eficiência na geração de resíduos nos terminais portuários que movimentam, de forma predominante, a carga geral, utilizando o método de análise envoltória de dados (DEA).

A partir da introdução, este trabalho apresenta na seção 2 o referencial teórico, na seção 3 , os dados das variáveis e o modelo DEA adotado, na seção 4 a análise dos resultados. A seção 5 apresenta a conclusão, as limitações encontradas e sugestões para novos estudos e, por fim, as referências utilizadas.

\section{REFERENCIAL TEÓRICO}

\subsection{Resíduos sólidos}

A legislação brasileira define resíduos sólidos como o bem resultante de atividades humanas em sociedade, cuja destinação final seja obrigatória ou não, nos estados sólidos ou semissólidos, assim como no estado gasoso desde que contidos em recipientes e no estado líquido desde que suas particularidades se tornem inviáveis o lançamento na rede pública de esgotos ou em corpos d'agua (Brasil, 2010).

Com isso, Brasil (2010) os classifica quanto à sua origem e ao grau de periculosidade. Quanto à origem;

a) Resíduos domiciliares: originados nas atividades domésticas em residências urbanas,

b) Resíduos de limpeza urbana: "originados da varrição, limpeza de logradouros e vias públicas e outros serviços de limpeza urbana”,

c) Resíduos industriais; "gerados nos processos produtivos e instalações industriais",

d) Resíduos de serviços de saúde: "gerados nos serviços de saúde, conforme definido em regulamento ou em normas estabelecidas pelos órgãos do Sisnama e do SNVS", 
e) Resíduos de serviços de transporte: "originados nas atividades de portos, aeroportos, terminais alfandegários, rodoviários e ferroviários e passagens de fronteira”, e entre outros (Brasil, 2010).

No que se refere à periculosidade;

a) Resíduos perigosos: em razão das características quanto à inflamabilidade, corrosividade, reatividade, toxicidade, patogenicidade, carcinogenicidade, teratogenicidade e mutagenicidade, os resíduos apresentam risco considerável à saúde pública ou à qualidade ambiental (Brasil, 2010);

b) Resíduos não perigosos: todos os resíduos que não se enquadram no item anterior (Brasil, 2010);

No Brasil, o Instituto Brasileiro de Meio Ambiente e dos Recursos Naturais Renováveis (IBAMA) tem catalogado os tipos de resíduos sólidos, por meio da Lista Brasileira de Resíduos Sólidos, publicada em na forma de Instrução Normativa (IN) $\mathrm{n}^{\mathbf{0}} 13$, publicado em 2012, que determina a obrigatoriedade no uso desta Lista nos empreendimentos e atividades licenciados ambientalmente pelo IBAMA na prestação de informações e no gerenciamento de resíduos sólidos, resíduos perigosos e rejeitos.(IBAMA, 2012). Com isso, conclui-se que os portos e os terminais portuários brasileiros devem utilizar a Lista Brasileira de Resíduo Sólidos.

Apesar desta obrigatoriedade legal, a Agência Nacional de Transportes Aquaviários (ANTAQ) orienta os portos brasileiros a adotarem o Manual Detalhado de Instalações Portuárias para Recepção de Resíduos, elaborado pela MARPOL 73/78 (convenção internacional para a prevenção da poluição por navios) como referência para o gerenciamento dos resíduos sólidos gerados nas atividades portuários. Este último não apresenta as tipologias de resíduos a serem considerados, e sim, as categorias por meio dos anexos I, II, III, IV e V do manual (ANTAQ, 2004).

\subsection{Geração de Resíduos em Portos}

O trabalho de Mohee et al (2012) apresentou uma previsão de resíduos gerados a partir da previsão de atracações no porto. Para isto, foi realizado o levantamento das informações quanto a atracação e carga movimentada no ano de 2008 - resultando em 2.015 atracações e 2,3 milhões de toneladas de carga conteinerizada movimentada. Nos anos entre 2009 e 2010, o montante de resíduos gerados foi de 5.010 toneladas. Ao considerar o ano de 2009 como o ano base, os autores previram 2.218 atracações. (Mohee et al., 2012).

Um outro trabalho que também merece atenção é o de Pereira et al (2014) que apresenta os procedimentos adotados no gerenciamento dos resíduos sólidos gerados no porto de Santos, situado no Brasil (Pereira et al., 2014).

O trabalho de Pereira et al (2014) possibilitou destacar o quantitativo de resíduos coletados pela empresa Marim Gerenciamento de Resíduos Ltda. ME, onde foi possível identificar as tipologias e representatividade dos resíduos gerados no porto de Santos. Conforme é possível observar a Figura 1, o entulho representa 33,64\% (588,58 toneladas); os resíduos orgânicos 28,89\% (505,54 toneladas); os resíduos comerciais 21,05\% (368,3 toneladas). Os resíduos classe I, madeira, adubo e recicláveis representaram juntos, $16,43 \%$ (287,47 toneladas) (Pereira et al., 2014). 


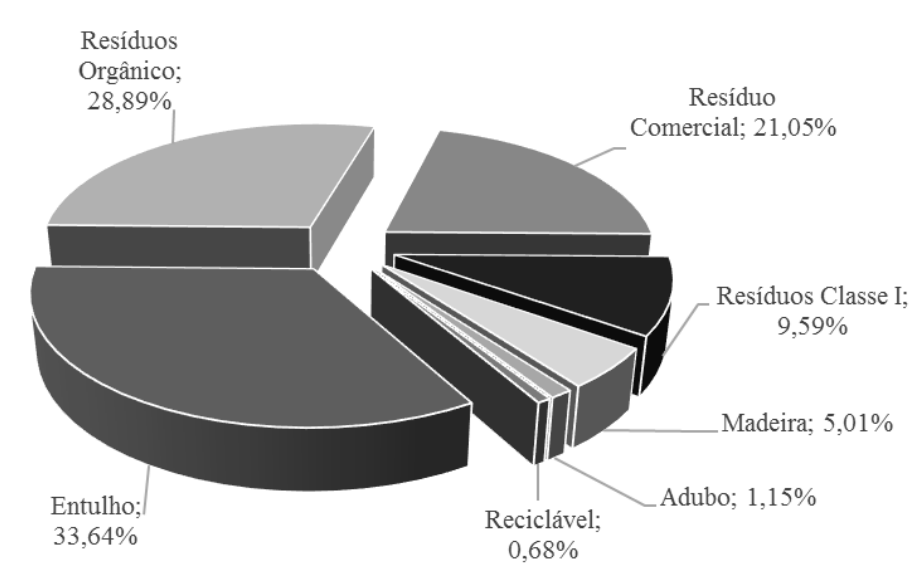

Figura 1- Porcentagem de resíduos coletados pela Marim Gerenciamento de Resíduos Ltda, situada no porto de Santos, nos primeiros meses de 2010.

Fonte: Adaptado de (Pereira et al., 2014)

\subsection{Análise Envoltória de Dados (DEA)}

A Análise Envoltória de Dados (DEA) foi proposta por Charnes et al. (1978) com o intuito de avaliar a eficiência técnica das escolas públicas primárias nos Estados Unidos da América (EUA). Com a difusão do DEA no mundo, diversas aplicações foram realizadas nos mais diversos setores econômicos, como por exemplo, no setor portuário, indústrias, setor de serviço, entre outros (Charnes et al., 1978; Cooper et al., 2006; Lins e Meza, 2000).

Um dos principais conceitos abordado em DEA é a definição de DMU (Decision Making Unit) - também conhecidas por Unidades Tomadoras de Decisão (UTD) - que são as entidades a que se deseja avaliar pelo DEA. As DMU's devem consumir os mesmos inputs para produzir os mesmos outputs. Com isso, a definição de DMU não abrange apenas o meio corporativo, mas também os governos, agências sem fins lucrativos, escolas, universidades, bancos, forças armadas, hospitais, portos, aeroportos, forças policiais, países, regiões, entre outros. (Bertoloto e Mello, 2011; Cooper et al., 2006; Sousa Júnior, 2010; Tiscoski, 2016).

O método DEA possibilita analisar a eficiência comparativa num dado conjunto de DMU's, onde é possível observar o desempenho de cada DMU perante o conjunto. Além disto, é possível construir uma fronteira eficiente a partir da relação dos outputs e dos inputs, de cada DMU, considerados no problema. As DMU's menos eficientes se situarão abaixo da fronteira eficiente, denominada de envoltória convexa (Acosta et al., 2011; Cooper et al., 2006; Lins e Meza, 2000; Rodrigues et al., 2015).

O cálculo da eficiência é dado pela razão entre a soma ponderada dos outpus e a soma ponderada dos inputs. Para isto, o modelo DEA atribui pesos aos inputs e outputs para cada DMU observada $\left(\mathrm{DMU}_{\mathrm{o}}\right)$. Em seguida, as $\mathrm{DMU}_{\mathrm{o}}$ são avaliadas perante o conjunto de DMU's selecionados, formando, assim, a fronteira eficiente de produção. As DMU's que eficientes servem de referência para as ineficientes - conhecidas também por benchmark (Acosta et al., 2011; Bertoloto e Mello, 2011; Charnes et al., 1978; Rodrigues et al., 2015).

\subsection{Modelos clássicos de DEA}

O método DEA dispõe de dois modelos clássicos; CCR - conhecido também por CRS (Constant Return to Scale) - e o BCC - conhecido também por VRS (Variable Return Scale). O modelo CCR opera com retornos constantes de escala, ou seja, a variação no consumo dos recursos é proporcional à obtenção dos produtos. Por outro lado, o modelo BCC não adota esta proporcionalidade, possibilitando que as DMU's consumam quantidades significativas de recursos e 
tenham retornos decrescentes de escala e vice-versa (Bertoloto e Mello, 2011; Charnes et al., 1978; Guedes et al., 2008; Santos e Sproesser, 2013).

Ambos os modelos possibilitam adotar duas orientações;

- Orientação a output: quando se deseja obter o máximo de produtos sem que altere a quantidade de insumos consumidos.

- Orientação a input: quando se deseja minimizar os recursos disponíveis sem que altere a quantidade de produtos obtidos. (Bertoloto e Mello, 2011; Charnes et al., 1978; Santos e Sproesser, 2013)

A Quadro 1 apresentam os trabalhos, nacionais e internacionais, que utilizaram DEA para avaliar o desempenho do setor portuário.

Quadro 1- Relação dos trabalhos publicados que utilizaram DEA no setor portuário.

\begin{tabular}{|c|c|c|c|c|}
\hline Ano & Autor & Modelo & Input & Output \\
\hline 2008 & Guedes et al,.. & $\mathrm{BCC}$ & $\begin{array}{c}\text { Quantidade de Berços } \\
\text { Quantidade de Funcionários } \\
\text { Área do terminal }\left(\mathrm{m}^{2}\right)\end{array}$ & $\begin{array}{l}\text { Teus/Guindaste; } \\
\text { Teus; }\end{array}$ \\
\hline 2014 & Rubem, et al,. & $\begin{array}{l}\text { CCR E } \\
\text { BCC }\end{array}$ & Input Unitário & $\begin{array}{c}\text { Número de atracações; } \\
\text { Movimentação de carga em } \\
\text { contêineres (TEU); } \\
\text { Movimentação de carga solta } \\
\text { (tonelada); } \\
\text { Movimentação de carga em } \\
\text { granel líquido (tonelada); } \\
\text { movimentação de granel sólido } \\
\text { (tonelada); }\end{array}$ \\
\hline 1993 & Roll e Hayuth & CCR & $\begin{array}{c}\text { Capital } \\
\text { No de funcionários } \\
\text { Tipo de Carga }\end{array}$ & $\begin{array}{l}\text { Nível de serviço } \\
\text { Movimentação de carga } \\
\text { Satisfação dos usuários } \\
\mathrm{N}^{\circ} \text { de atracações }\end{array}$ \\
\hline 1999 & Martinez-Budria et al & $\mathrm{BCC}$ & $\begin{array}{l}\text { Despesas com pessoal } \\
\text { Taxas de depreciação }\end{array}$ & $\begin{array}{c}\text { Total de carga movimentada } \\
\text { Receita obtida no aluguel de } \\
\text { facilidades } \\
\text { Outros gastos }\end{array}$ \\
\hline 2001 & Tongzon & CCR & $\begin{array}{c}\mathrm{N}^{\circ} \text { de guindaste } \\
\mathrm{N}^{\mathrm{o}} \text { de berços de atracação } \\
\mathrm{N}^{\mathrm{o}} \text { de rebocadores } \\
\mathrm{N}^{\mathrm{o}} \text { de funcionários } \\
\text { Área do terminal } \\
\text { Delay time }\end{array}$ & $\begin{array}{l}\text { Movimentação de contêiner em } \\
\text { TEU's } \\
\text { Movimentação TEU's por hora de } \\
\text { trabalho/navio }\end{array}$ \\
\hline 2001 & Valentine e Gray & CCR & $\begin{array}{l}\text { Tamanho dos Berços } \\
\text { Investimento }\end{array}$ & $\begin{array}{l}\mathrm{N}^{\mathrm{o}} \text { de contêineres } \\
\text { Total de toneladas movimentadas }\end{array}$ \\
\hline 2002 & Itoh & CCR e BCC & $\begin{array}{l}\text { Área do terminal } \\
\mathrm{N}^{\circ} \text { de berços } \\
\mathrm{N}^{\mathrm{o}} \text { de funcionários } \\
\mathrm{N}^{\mathrm{o}} \text { de guindastes }\end{array}$ & TEU's \\
\hline 2004 & Park e De & CCR e BCC & $\begin{array}{l}\text { Capacidade dos berços em } \\
\text { receber navios } \\
\text { Capacidade de manuseio de } \\
\text { carga }\end{array}$ & $\begin{array}{c}\text { Movimentação de carga } \\
\text { No de chamadas de navios }^{\text {Receitas }} \\
\text { Satisfação do cliente }\end{array}$ \\
\hline
\end{tabular}




\begin{tabular}{|c|c|c|c|c|}
\hline Ano & Autor & Modelo & Input & Output \\
\hline 2013 & Chang & SDM-DEA & $\begin{array}{c}\mathrm{N}^{\mathrm{o}} \text { de trabalhadores empregados } \\
\text { Comprimento do cais } \\
\text { Área do terminal } \\
\text { Energia consumida (TOE) }\end{array}$ & $\begin{array}{l}\text { Quantidade de embarcações } \\
\text { Carga movimentada } \\
\text { Emissão de } \mathrm{CO}_{2}\end{array}$ \\
\hline 2013 & Sousa Jr., et al & CCR & $\begin{array}{c}\text { Calado (m) } \\
\text { Extensão do berço (m) } \\
\text { Capacidade estática (TEU) }\end{array}$ & $\begin{array}{c}\text { Quantidade de navios } \\
\text { Movimentação de carga (TEU) } \\
\text { Movimentação horária da carga } \\
(\mathrm{Un} / \mathrm{h})\end{array}$ \\
\hline
\end{tabular}

Fonte: Elaboração Própria

O trabalho de Guedes et al,. (2008) compara o modelo DEA utilizado por Rios, Maçada e Backer (2004) e o utilizado em sua pesquisa. Enquanto que Rios, Maçada e Backer (2004) utilizaram o modelo CCR orientado a input considerando 4 inputs e 1 output, o modelo proposto por Guedes et al,. (2008) utilizou o modelo DEA BCC orientado a output considerando como inputs: número de berços, tamanho da área do terminal e quantidade de funcionários. E os outputs foram: a quantidade de TEU's por guindaste (relação de produtividade) e quantidade de TEU's movimentados. Entretanto, os respectivos autores utilizaram DMU's artificiais como um método alternativos de simulação de um conjunto de restrições aos pesos. (Guedes et al., 2008; Rios et al., 2004)

O artigo de Rubem et al,. (2014) utilizou dois métodos para avaliar o desempenho das DMU's que foram o DEA CCR e BCC, ambos orientados a output na formulação do envelope e o método de Copeland. Os autores visavam avaliar a importância relativa de cada unidade do setor portuário brasileiro para o comercio nacional, dado o tipo de carga movimentada por cada unidade portuária. Para isso, os autores criaram um conjunto de clusters e segregaram tais portos conforme o perfil da carga de cada unidade portuário. Neste artigo, a própria unidade portuária foi considerada como o input (input unitário) e para output foram considerados o número de atracações, quantidade de carga movimentada em contêineres (TEU), tonelagem movimentada de carga solta, tonelagem movimentada de carga em granel líquido; e a tonelagem de carga movimentada em granel sólido. (Rubem et al., 2014)

O artigo de Roll e Hayuth (1993) é considerado o trabalho pioneiro na defesa da aplicação de DEA no setor portuário. Entretanto, os autores limitaram na apresentação teórica ao invés da aplicação propriamente dita. (Roll e Hayuth, 1993)

O trabalho de Martinez-Budria et al (1999) aplicou o modelo DEA-BCC com o intuito de avaliar o desempenho de 26 portos contêineres espanhóis, sendo estes segregados em três grupos conforme o grau de complexidade de cada um. (Martinez-Budría et al., 1999)

Tongson (2001) avaliou o desempenho de 16 terminais de diferentes países considerando dois outputs, movimentação de contêiner (TEU) e a movimentação de contêineres (TEU) por hora de trabalho por navio, e seis inputs, número de guindaste, número de berços de atracação, número de rebocadores, número de funcionários, área do terminal e Delay time. (Tongzon, 2001)

O artigo de Chang (2013) analisou a eficiência ambiental em portos na Coreia utilizando o modelo DEA-Aditivo, considerando dados de desempenho ambiental e econômico, estimando, assim, o potencial de redução de $\mathrm{CO}_{2}$ pelos portos do estudo. $\mathrm{O}$ artigo determina que estes portos foram ineficientes no ponto de vista econômico, e eficientes ao considerar o desempenho ambiental e econômico simultaneamente. O modelo adotado no trabalho foi o Slacks-Based Measure Data Envelopment Analysis Model (SBM-DEA) para avaliar a eficiência ambiental dos portos na Coreia do Sul. Além das variáveis de entrada e saída, Chang (2013) segrega as variáveis de saída em outputs desejáveis e outputs indesejáveis, como é o caso da emissão de $\mathrm{CO}_{2}$. (Chang, 2013) 
Como é possível observar na Quadro 1, dos 10 trabalhos levantados, apenas um diz respeito ao desempenho ambiental portuário - Chang (2013). Com isso, a partir deste levantamento é possível afirmar que a quantidade de trabalhos acadêmicos disponíveis que utilizaram DEA nesta temática é baixa.

Os outputs indesejados são externalidades inerentes ao processo produtivo, como por exemplo, à emissão de $\mathrm{CO}_{2}$, geração de resíduos numa fábrica, entre outros. Logo, não é possível considerar que quanto maior a quantidade de outputs indesejados, melhor (Chang, 2013; RosanoPena et al., 2013; Tschaffon e Meza, 2011).

Com isso, os outputs indesejáveis são tratados para que a eficiência das DMU's seja calculada corretamente. Os autores Tschaffon e Meza (2011) apresentam quatro abordagens na estruturação do modelo DEA para incorporar os outputs indesejados ao modelo DEA, que são; Additive Inverse (ADD), Incorporating Undesirable Outputs as Inputs (INP), Multiplicative Inverse (MLT) e Translation (TR $\beta$ ). (Tschaffon e Meza, 2011)

Neste artigo foi adotado à abordagem Multiplicative Inverse (MLT), desenvolvido por Golany e Roll (1989). Esta abordagem transforma os outputs indesejáveis em outputs desejáveis por meio do seu inverso, expresso pela função $f(U)=1 / u$. Entretanto, não é possível utilizar esta abordagem se o valor do output indesejável for igual zero. (Tschaffon e Meza, 2011).

Durante a pesquisa, os resultados das análises apresentaram diversas DMU's eficientes. Com isso, foram levantados dois métodos, como forma de contornar o problema da baixa discriminação e a fim de ordenar as DMU's, que são: Fronteira Invertida e Avaliação Cruzada. (Tschaffon e Meza, 2011).

Segundo Tschaffon e Meza (2011), a Avaliação Cruzada não pode ser aplicada no modelo BCC, restando o método da Fronteira Invertida em que permite identificar as DMU's eficientes tanto pela fronteira padrão quanto pela fronteira invertida. Para que as DMU's sejam eficientes é necessário que, além de situarem na fronteira eficiente, é necessário que se situem o mais distante possível da fronteira invertida. Caso os valores da eficiência padrão e invertida sejam máximos para uma determinada DMU, esta é considerada uma falso-positivo. (Cortez et al., 2010; Tschaffon e Meza, 2011).

A forma para ordenar as DMU's é a partir da média aritmética entre à fronteira eficiente e a ineficiente em relação à fronteira invertida, dado pela Equação 1. (Giacomello e Oliveira, 2014; Leta et al., 2005; Tschaffon e Meza, 2011)

Além disto, a eficiência composta normalizada (composta*) é obtida por meio da relação entre a eficiência composta da DMU em análise e do maior valor da eficiência composta do conjunto de DMU's (Equação 2). (Giacomello e Oliveira, 2014).

\section{MATERIAIS E MÉTODOS}

\subsection{Materiais}

As variáveis consideradas neste estudo foram quantidade de carga movimentada (toneladas), quantidade de atracações e quantidade de resíduos gerados (toneladas), no período de tempo entre 2011 e 2013.

O quantitativo de resíduos sólidos foi extraído por meio do projeto realizado em parceria com à Secretaria Especial de Portos da Presidência da República (SEP/PR) e à COPPE/UFRJ, no que permitiu o levantamento do inventário de resíduos de 22 portos brasileiros. Além disto, foi possível identificar que, em diversos portos, a infraestrutura mínima necessária para o manejo 
adequado dos resíduos sólidos está aquém, conforme determina a ANVISA (2008) por meio da RDC 56/2008 - Regulamento Técnico de Boas Práticas Sanitárias no Gerenciamento de Resíduos Sólidos nas Áreas de Portos, Aeroportos, Passagens de Fronteiras e Recintos Alfandegários. (ANVISA, 2008; SEP e UFRJ, 2014)

Os dados de carga movimentada e quantidade de atracações foram extraídos do Sistema de Informações Gerenciais (SIG) da ANTAQ.

Segundo SEP e UFRJ (2014), os dados da geração de resíduos foram extraídos de documentos de fontes oficiais disponíveis na internet. Com isso, os dados da geração de resíduos foram extraídos dos Relatórios de Diagnóstico do Programa de Conformidade. Os dados de carga movimentada e atracação foram extraídos do Sistema de Informações Gerenciais (SIG). O período considerado compreende os anos de 2011 a 2013.

\subsubsection{Dados da geração de resíduos sólidos nos portos brasileiros}

Segundo SEP e UFRJ (2014) disponibilizaram os inventários de resíduos sólidos de 22 portos brasileiros, que são: Rio de Janeiro, Rio Grande, Itaguaí, Paranaguá, São Francisco do Sul, Vila do Conde, Itaqui, Natal, Aratu-Candeias, Suape, Fortaleza, Maceió, Recife, Belém, Itajaí, Vitória, Imbituba, São Sebastião, Salvador, Cabedelo Ilhéus e Santos. Com exceção do porto de Santos, o montante de resíduos gerados no período supracitado foi pouco mais de 394 mil toneladas de resíduos. (SEP e UFRJ, 2014)

Para o levantamento do inventário de resíduos sólidos nos portos, SEP e UFRJ (2014) desenvolveu um procedimento padrão que foi aplicado primeiro no porto do Rio de Janeiro como teste e, então, após ajustes nos procedimentos padrão, aplicados nos demais portos.

O procedimento padrão contou com o levantamento de documentos que comprovam o armazenamento, tratamento, transporte e destinação dos resíduos gerados junto as autoridades portuárias. Desta forma, é importante destacar que há três tipos de documentos, que são, inventários de resíduos, manifesto de transportes e o plano de gerenciamento de resíduos (SEP e UFRJ, 2014).

O inventário de resíduos é o documento gerado pelos terminais arrendados ou terceirizados que prestam serviço dentro da área portuária. Este documento é um resumo mensal da movimentação de resíduos. O manifesto de transportes, em geral, este documento é normatizado pela secretaria estadual ou municipal de meio ambiente, que exige o registro da atividade de transporte de resíduos sólidos. A única tipologia de resíduo que está isento dessa exigência são os resíduos classificados como lixo comum. E, o plano de gerenciamento de resíduos "é um documento que aponta as diretrizes para os resíduos sólidos, desde a geração até a destinação, sob a responsabilidade da Administração Portuária. " (SEP e UFRJ, 2014)

O resultado do levantamento identificou que o porto do Rio de Janeiro gerou um montante aproximado de 298 mil toneladas, o que representa $61,4 \%$ do total de resíduos gerados nos portos (Figura 2). O segundo que mais gerou resíduo foi o porto de Itaguaí, que contabilizou um total aproximado de 49 mil toneladas (10,11\%), muito distante do porto do Rio de Janeiro. Em seguida, os portos de Rio Grande, Paranaguá, Vila do Conde, São Francisco do Sul e Salvador geraram aproximadamente 46 mil toneladas $(9,52 \%), 30$ mil toneladas $(6,32 \%), 19$ mil toneladas $(3,99 \%)$, 12 mil toneladas (2,45\%), 8 mil toneladas (1,7\%). (Freitas, 2014; SEP e UFRJ, 2014) 


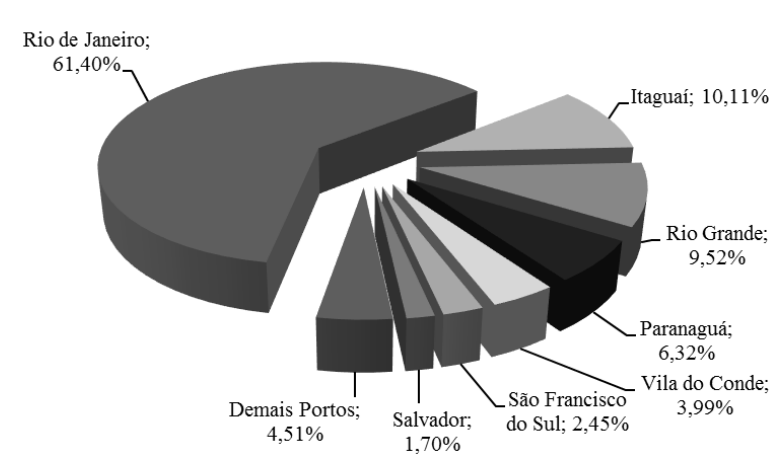

Figura 2- Relação de resíduos gerados nos portos, no período entre 2011 e 2013

Fonte: Adaptado de (SEP e UFRJ, 2014)

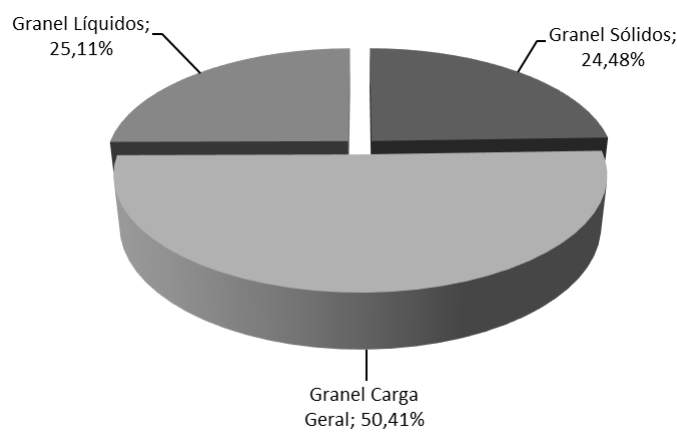

Figura 3- Percentual da quantidade de resíduos gerados nos terminais portuários, por natureza da carga, no período de 2011 a 2013. Fonte: (SEP e UFRJ, 2014)

Por fim, os portos que totalizaram um valor inferior $1 \%$ na quantidade de resíduos gerados foram incluídos na categoria "Demais Portos", que são; Itaqui, Recife, Belém, Natal, AratuCandeias, Suape, Vitória, Fortaleza, Maceió, Itajaí, São Sebastião, Cabedelo, Imbituba e Ilhéus. (SEP e UFRJ, 2014)

A partir da Figura 3, os terminais de Carga Geral foram responsáveis por quase a metade $(50,41 \%)$ do quantitativo total de resíduos gerados pela amostra, o que em valores absolutos representam, aproximadamente, 90 mil toneladas. Os terminais de granel líquido foram responsáveis por $25,11 \%$ (quase 45 mil toneladas) e, por fim, $24,48 \%$ (quase 44 mil toneladas) de granel sólido. (SEP e UFRJ, 2014).

\subsubsection{Carga movimentada e atracação}

A movimentação de carga apresentou uma realidade diferente quando comparado com a geração de resíduos. Do total de cargas movimentadas - pouco mais de 338 milhões de toneladas -, $76,85 \%$ foi de granel sólido (260 milhões de toneladas, aproximadamente), 7,46\% granel líquido (25 milhões de toneladas, aproximadamente) e, por fim, 15,69\% carga geral (53 milhões de toneladas, aproximadamente) (Figura 4). (ANTAQ, 2015)

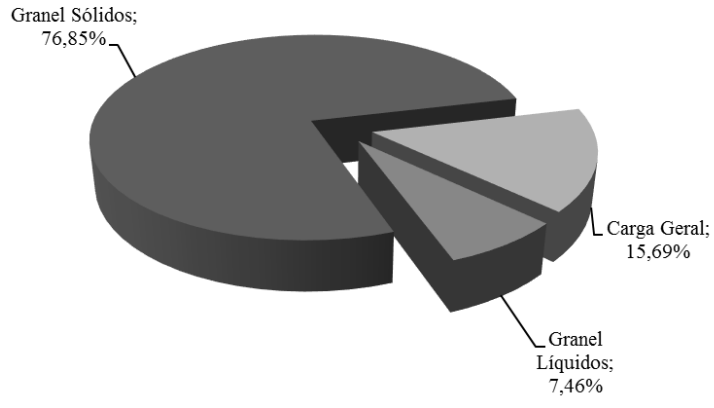

Figura 4- Percentual de carga movimentada nos terminais portuários, por natureza da carga, no período de 2011 a 2013. Fonte: (ANTAQ, 2015)

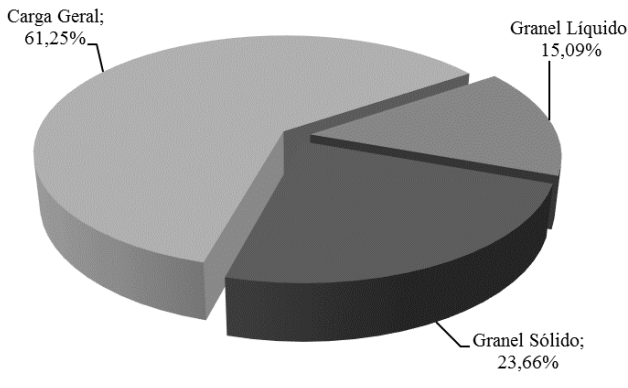

Figura 5- Percentual de atracações nos terminais portuários por natureza da carga, no período de 2011 a 2013.

Fonte: (ANTAQ, 2015)

Nos dados de atracação (Figura 5), a carga geral representou 61,25\% (pouco mais de 13 mil atracações). Os terminais de graneis sólidos e líquidos representaram, respectivamente, 23,66\% e $15,09 \%$ (pouco mais de cinco mil e quase 3,3 mil atracações, respectivamente). (ANTAQ, 2015). 
Ao analisar as duas primeiras variáveis (resíduos gerados e carga movimentada), não foi possível estabelecer uma relação direta entre ambas. Pois, como é possível observar na Figura 3, os terminais de granel sólido - por exemplo -, geraram 24,48\% de resíduos enquanto a movimentação de carga representou 76,85\% da amostra. O mesmo ocorre nos terminais de Carga Geral e Granel Líquido. Por outro lado, os terminais de carga geral foram os que mais geraram resíduos e os que apresentaram a maior quantidade de atracações da amostra. Entretanto, os terminais de granel líquido foram os que menos tiveram atracações, sendo que estes não foram os que menos geraram resíduos.

\subsection{Método}

A partir das três variáveis apresentadas (carga movimentada, atracação e resíduos sólidos), duas são outputs desejáveis (carga movimentada e atracação) e um output indesejável (resíduos sólidos), que foi transformado num output desejado conforme o método MLT. Sendo assim, foi considerado o input unitário nas análises.

Neste artigo foi adotado o modelo DEA-BCC orientado a output. Além disto, foi utilizado a fronteira invertida com o intuito de aumentar a discriminação e ordenar as DMU's eficientes, conforme Equação 1 e Equação 2.

$$
\begin{aligned}
\text { Efic. Composta } & =\frac{\text { Efic.Padrão }+(1-\text { Efic. Invertida })}{2} \\
\text { Efic. Composta } * & =\frac{\text { Efic.Composta }}{\text { Máximo (Efic.Composta) }}
\end{aligned}
$$

Equação 1

Equação 2

Nas análises, os terminais portuários precisam ser homogêneos, logo, estes foram segregados em três clusters considerando as naturezas das cargas; granel sólido, granel líquido e carga geral. Para integrar o cluster, a representatividade da natureza da carga deve ser de no mínimo $60 \%$ do total de carga movimentada do terminal, no período que compreende 2011 e 2013. Nas análises, considerou o cluster que mais gerou resíduos da amostra. Sendo assim, o cluster carga geral foi selecionado, conforme é possível observar na Figura 3.

O cluster Carga Geral é composto, inicialmente, por 26 terminais portuários. Entretanto, cinco terminais foram retirados da lista de DMU's porque geraram menos de uma tonelada de resíduos sólidos, restando, assim, 21 terminais. A Tabela 1 apresenta a relação das DMU's que foram analisadas e os valores de resíduos sólidos gerados - transformados conforme a abordagem MLT - e carga movimentada, em toneladas, assim como a quantidade de atracação. (ANTAQ, 2015; SEP e UFRJ, 2014)

\begin{tabular}{|c|c|c|c|c|c|}
\hline DMU & Porto & $\begin{array}{c}\text { Terminal/Operador } \\
\text { Portuário } \\
\end{array}$ & $\begin{array}{c}\left(\text { Resíduos }^{-1} \times 10^{5}\right) \\
\left(\text { ton }^{-1} \times 10^{5}\right)\end{array}$ & $\begin{array}{c}\text { Carga } \\
\text { (ton) }\end{array}$ & Atracação \\
\hline 1 & Rio de Janeiro & Libra Terminais SA & 2,73 & 5.908 .317 & 2.188 \\
\hline 2 & Rio de Janeiro & $\begin{array}{l}\text { Multi-Rio Operações } \\
\text { Portuárias SA }\end{array}$ & 3,10 & 10.226 .970 & 3.081 \\
\hline 3 & Itaguaí & Sepetiba Tecont SA & 8,67 & 11.506 .369 & 2.716 \\
\hline 4 & Natal & Seamaster Ltda & 43,81 & 425 & 3 \\
\hline 5 & Belém & $\begin{array}{l}\text { Cma Cgm Do Brasil } \\
\text { Agencia Maritima Ltda }\end{array}$ & 54,43 & 12.615 & 6 \\
\hline 6 & Vitória & Autoridade Portuária & 66,84 & 586 & 1 \\
\hline 7 & $\begin{array}{l}\text { São Francisco } \\
\text { do Sul }\end{array}$ & $\begin{array}{l}\text { Tesc - Terminal Santa } \\
\text { Catarina SA }\end{array}$ & 69,03 & 7.533 .834 & 1.160 \\
\hline 8 & Itajaí & Apm Terminals Itajaí SA & 116,15 & 12.329 .930 & 2.017 \\
\hline
\end{tabular}

Tabela 1- Relação das DMU's e as variáveis consideradas no problema 


\begin{tabular}{|c|c|c|c|c|c|}
\hline DMU & Porto & $\begin{array}{c}\text { Terminal/Operador } \\
\text { Portuário } \\
\end{array}$ & $\begin{array}{c}\left(\text { Resíduos }^{-1} \times 10^{5}\right) \\
\left(\text { ton }^{-1} \times 10^{5}\right)\end{array}$ & $\begin{array}{c}\text { Carga } \\
\text { (ton) }\end{array}$ & Atracação \\
\hline 9 & Suape & Wilson Sons SA & 175,44 & 19.962 & 3 \\
\hline 10 & Paranaguá & $\begin{array}{l}\text { Agencia Maritima Orion } \\
\text { Ltda }\end{array}$ & 199,61 & 2.295 & 5 \\
\hline 11 & Rio Grande & $\begin{array}{l}\text { Sagres Agenciamento } \\
\text { Marítimo Ltda }\end{array}$ & 314,72 & 2.123 .566 & 753 \\
\hline 12 & Paranaguá & $\begin{array}{l}\text { Oceanus Agencia } \\
\text { Maritima SA }\end{array}$ & 795,68 & 7.030 & 2 \\
\hline 13 & Paranaguá & $\begin{array}{l}\text { Transgolf Agencia } \\
\text { Maritima Ltda }\end{array}$ & 859,72 & 1.236 & 1 \\
\hline 14 & Paranaguá & $\begin{array}{l}\text { Marcon Servicos de } \\
\text { Despachos Em Geral Ltda }\end{array}$ & $1.288,71$ & 2.397.312 & 991 \\
\hline 15 & Belém & Iss Marine Service Ltda & $1.774,31$ & 751 & 3 \\
\hline 16 & Vila do Conde & $\begin{array}{l}\text { B F Fortship (Pa) Agencia } \\
\text { Maritima Ltda }\end{array}$ & $4.098,36$ & 12.502 & 1 \\
\hline 17 & Natal & $\begin{array}{l}\text { Superservice Inspeções E } \\
\text { Operações Portuárias Ltda }\end{array}$ & $7.531,25$ & 58.168 & 55 \\
\hline 18 & Fortaleza & $\begin{array}{l}\text { Brandao Filhos Fortship } \\
\text { Pe Agencia Maritima Ltda }\end{array}$ & $10.424,27$ & 266.665 & 171 \\
\hline 19 & Rio de Janeiro & $\begin{array}{l}\text { Oceanus Agencia } \\
\text { Maritima SA }\end{array}$ & $22.146,19$ & 94.579 & 55 \\
\hline 20 & Fortaleza & $\begin{array}{l}\text { Tracol - Agencia } \\
\text { Marítima Transc. Ltda }\end{array}$ & $59.171,60$ & 13.546 & 1 \\
\hline 21 & Vila do Conde & Amazon Agency Ltda & $66.666,67$ & 2.913 & 2 \\
\hline
\end{tabular}

Fonte: (ANTAQ, 2015; SEP e UFRJ, 2014)

Para que seja possível comparar os valores de carga movimentada, atracação e resíduos gerados entre os portos de Louis Harbour e Rio de Janeiro, foi necessário calcular a previsão de carga movimentada no ano de 2009, da seguinte forma: (cargamovimentada $a_{2008} \times$ $\frac{\text { atracação } o_{2009}}{\text { atracação } o_{2008}}$, conforme Tabela 2. Os valores das variáveis do porto do Rio de Janeiro são referentes aos terminais da Tabela 1. Além disto, com o intuito de facilitar esta análise foi adotado o valor absoluto dos resíduos gerados em ambos os portos.

Tabela 2- Comparação dos valores apresentados pelas variáveis consideradas no problema entre os portos do Rio de Janeiro de Louis Harbour

\begin{tabular}{|c|c|c|c|}
\hline Porto & Resíduos Gerados & Carga (ton) & Atracação \\
\hline Rio de Janeiro (2011) & $68.897,86$ & $16.229 .866,00$ & 5.324 \\
\hline Louis Harbour (2009) & 5.010 & $2.531 .712,16$ & 2.218 \\
\hline
\end{tabular}

Fonte: Adaptado de (Mohee et al., 2012; SEP e UFRJ, 2014)

A partir da Tabela 2 é possível observar que o porto do Rio de Janeiro atracou $40 \%$ mais navios, movimentou $541 \%$ mais cargas e gerou $1.275 \%$ mais resíduos na comparação com o porto de Louis Harbour. Além disto, o porto do Rio de Janeiro gerou 12,94 toneladas de resíduo por embarcação atracada, enquanto que o outro porto gerou 2,26 toneladas por atracação. Para cada 235,56 toneladas de carga movimentada, o porto do Rio de Janeiro gera uma tonelada de resíduo, enquanto que o porto Louis Harbour precisa movimentar 505,33 toneladas para gerar a mesma quantidade de resíduo. A partir disto, é possível concluir que o porto Louis Harbour se mostrou mais eficiente na geração de resíduos nas operações de movimentação de carga e atracação de navios, quando comparado com o porto do Rio de Janeiro. 


\section{RESULTADOS E DISCUSSÃO}

Nas análises do modelo DEA, os terminais que compõem a fronteira eficiente foram: Libra Terminais SA (DMU 1), Multi-Rio Operações Portuárias SA (DMU 2), Sepetiba Tecont SA (DMU 3), Apm Terminals Itajaí SA (DMU 9), Marcon Servicos de Despachos em Geral Ltda (DMU 14), Superservice Inspeções e Operações Portuárias Ltda (DMU 17), Brandao Filhos Fortship Pe Agencia Maritima Ltda (DMU 18) e Amazon Agency Ltda (DMU 21).

A elevada quantidade de DMU's na fronteira eficiente torna a análise pouco útil, pois mascara as DMU's falsas eficientes, além da baixa discriminação entre as DMU's. Para sanar este inconveniente, foi utilizado o método da fronteira invertida que, além de aumentar a discriminação, ordenar as DMU's eficientes do conjunto.

A partir disto, o terminal mais eficiente foi o Brandao Filhos Fortship Pe Agencia Maritima Ltda (DMU 18), situado no porto de Fortaleza. Para isto, o modelo desconsiderou à variável carga movimentada. Além disto, a DMU 18 apresentou o quarto maior valor na variável inverso do resíduo e foi o oitavo terminal que mais obteve atracações da amostra. Apesar de ser a mais eficiente da amostra, a DMU 18 não foi referência para nenhuma outra, a não ser por ela mesma.

O segundo terminal mais eficiente foi o Superservice Inspeções e Operações Portuárias Ltda (DMU 17), situado no porto de Natal. O modelo atribuiu pesos nas variáveis atracação e resíduo, com uma diferença no valor do peso atribuído para a atracação que, por sua vez, foi ligeiramente maior que a DMU 18, conforme é possível observa na Tabela 1. O terminal Marcon Serviços de Despachos em Geral Ltda, situado no porto de Paranaguá (DMU 14), atribuiu pesos às variáveis quanto ao resíduo e atracação. Apesar da DMU 14 não ser a mais eficiente do conjunto, esta é referência para as DMU's 5, 13, 15 e 19. (Tabela 3 e Tabela 4). Entretanto, a DMU 14 não é a única referência destas DMU's. Ao analisar de forma gráfica, a DMU 5, por exemplo, está a 0,8964 - de uma escala de zero a um - mais próxima da DMU 14 e 0,1036 da DMU 21. Por outro lado, a DMU 13 está a 0,709 mais próxima da DMU 14 e 0,093 mais próxima da DMU 21. Neste último caso, a DMU 13 assume mais as características da DMU 21 do que da DMU 14.

O quarto terminal mais eficiente foi a Apm Terminals Itajaí S.A. (DMU 8), situado no porto de Itajaí. Este terminal foi o que mais movimentou carga da amostra, o décimo sexto com o maior valor para o inverso do resíduo e o quarto com mais atracações. Apesar disto, o modelo desconsiderou das análises a variável de atracação, atribuiu peso apenas nas variáveis quanto ao resíduo e carga movimentada. A eficiência invertida foi de 0,284 e foi referência para as DMU's 7, 9, 16 e 20. (Tabela 3 e Tabela 4). A única DMU que apresentou valor igual a um de referência para a DMU 8 foi a DMU 7. As demais apresentaram valores que confirmam a proximidade com a DMU 21.

A Amazon Agency Ltda (DMU 21), situada no porto de Vila do Conde, apresentou 50\% de ineficiência. Os pesos foram atribuídos da mesma forma que a DMU 8, pois, esta DMU foi a que apresentou o maior valor para o inverso do resíduo da amostra. A quantidade de atracações foi baixa o suficiente para que o modelo desconsiderasse da análise. A DMU 21 foi referência para as DMU's 4, 5, 6, 9, 10,11, 12, 13, 15, 16, 19 e 20. (Tabela 3 e Tabela 4). Destas, as que estão mais próximas, pelo menos 0,50, são; DMU 6 (0,7558), DMU 9 (0,6189), DMU 10 (0,6487), DMU 12 (0,9474), DMU 13 (0,9290), DMU 15 (0,8993), DMU 16 (0,9840), DMU 19 (0,8579) e DMU 20 $(0,9989)$.

O terminal Sepetiba Tecon S.A. (DMU 3), situado no porto de Itaguaí, apresentou valor de 0,743 na eficiência invertida, ou seja, o terminal está muito próximo da fronteira de ineficiência. O modelo desconsiderou a variável resíduo nas análises, atribuindo pesos apenas nas variáveis de atracação e carga movimentada. 
Os terminais Multi-Rio Operações Portuárias S.A. (DMU 2) e Libra Terminais S.A. (DMU 1) estão situados no porto do Rio de Janeiro e apresentaram os mesmos valores para os pesos. Em ambos os casos, o modelo desconsiderou a variável carga movimentada. Entretanto, a DMU 1 é uma falso-positiva por situar-se na fronteira eficiente e na fronteira de ineficiência. Ou seja, na avaliação benevolente do modelo DEA, o terminal é eficiente e na avaliação pessimista, o terminal também é "eficiente" (Tabela 3 e Tabela 4).

Tabela 3- Resultados da avaliação considerando as três variáveis (resíduo, carga e atracação).

\begin{tabular}{|l|l|c|c|c|c|c|}
\hline \multicolumn{1}{|c|}{ Porto } & Terminal/Operador Portuário & DMU & Padrão & Invertida & Composta & Composta* \\
\hline Rio de Janeiro & Libra Terminais SA & 1 & 1,000000 & 1,000000 & 0,500000 & 0,501586 \\
\hline Rio de Janeiro & Multi-Rio Operações Portuárias SA & 2 & 1,000000 & 0,880645 & 0,559677 & 0,561452 \\
\hline Itaguá & Sepetiba Tecont SA & 3 & 1,000000 & 0,734371 & 0,632814 & 0,634821 \\
\hline Natal & Seamaster Ltda & 4 & 0,001630 & 1,000000 & 0,000815 & 0,000818 \\
\hline Belém & $\begin{array}{l}\text { Cma Cgm Do Brasil Agencia } \\
\text { Maritima Ltda }\end{array}$ & 5 & 0,006753 & 0,804256 & 0,101248 & 0,101569 \\
\hline Vitória & Autoridade Portuária & 6 & 0,001327 & 1,000000 & 0,000663 & 0,000665 \\
\hline $\begin{array}{l}\text { São Francisco } \\
\text { do Sul }\end{array}$ & Tesc - Terminal Santa Catarina SA & 7 & 0,611020 & 0,482902 & 0,564059 & 0,565848 \\
\hline Itajaí & Apm Terminals Itajaí SA & 8 & 1,000000 & 0,284715 & 0,857643 & 0,860362 \\
\hline Suape & Wilson Sons SA & 9 & 0,004247 & 0,373146 & 0,315551 & 0,316551 \\
\hline Paranaguá & Agencia Maritima Orion Ltda & 10 & 0,004615 & 0,304664 & 0,349976 & 0,351085 \\
\hline Rio Grande & $\begin{array}{l}\text { Sagres Agenciamento Marítimo } \\
\text { Ltda }\end{array}$ & 11 & 0,329544 & 0,133382 & 0,598081 & 0,599978 \\
\hline Paranaguá & Oceanus Agencia Maritima SA & 12 & 0,012597 & 0,500000 & 0,256299 & 0,257111 \\
\hline Paranaguá & Transgolf Agencia Maritima Ltda & 13 & 0,013860 & 1,000000 & 0,006930 & 0,006952 \\
\hline Paranaguá & $\begin{array}{l}\text { Marcon Servicos De Despachos Em } \\
\text { Geral Ltda }\end{array}$ & 14 & 1,000000 & 0,033563 & 0,983218 & 0,986336 \\
\hline Belém & Iss Marine Service Ltda & 15 & 0,029531 & 0,671537 & 0,178997 & 0,179565 \\
\hline Vila do Conde & $\begin{array}{l}\text { B F Fortship (Pa) Agencia Maritima } \\
\text { Ltda }\end{array}$ & 16 & 0,062473 & 1,000000 & 0,031237 & 0,031336 \\
\hline Natal & $\begin{array}{l}\text { Superservice Inspeções E } \\
\text { Operações Portuárias Ltda }\end{array}$ & 17 & 1,000000 & 0,018182 & 0,990909 & 0,994051 \\
\hline Fortaleza & $\begin{array}{l}\text { Brandao Filhos Fortship Pe } \\
\text { Agencia Maritima Ltda }\end{array}$ & 18 & 1,000000 & 0,006322 & 0,996839 & 1,000000 \\
\hline Rio de Janeiro & Oceanus Agencia Maritima SA & 19 & 0,385964 & 0,018182 & 0,683891 & 0,686060 \\
\hline Fortaleza & $\begin{array}{l}\text { Tracol - Agencia Marítima Transc. } \\
\text { Ltda }\end{array}$ & 20 & 0,888461 & 1,000000 & 0,444231 & 0,445639 \\
\hline Vila do Conde & Amazon Agency Ltda & 21 & 1,000000 & 0,500000 & 0,750000 & 0,752378 \\
\hline
\end{tabular}

Fonte: Elaboração Própria

Tabela 4- Benchmarks das DMU's na análise das três variáveis

\begin{tabular}{|l|c|c|c|c|c|c|c|c|}
\hline \multicolumn{1}{|c|}{ DMU } & DMU 1 & DMU 2 & DMU 3 & DMU 8 & DMU 14 & DMU 17 & DMU 18 & DMU 21 \\
\hline DMU 1 & 1,000000 & 0,000000 & 0,000000 & 0,000000 & 0,000000 & 0,000000 & 0,000000 & 0,000000 \\
\hline DMU 2 & 0,000000 & 1,000000 & 0,000000 & 0,000000 & 0,000000 & 0,000000 & 0,000000 & 0,000000 \\
\hline DMU 3 & 0,000000 & 0,000000 & 1,000000 & 0,000000 & 0,000000 & 0,000000 & 0,000000 & 0,000000 \\
\hline DMU 4 & 0,000000 & 0,596964 & 0,000000 & 0,000000 & 0,000000 & 0,000000 & 0,000000 & 0,403036 \\
\hline DMU 5 & 0,000000 & 0,000000 & 0,000000 & 0,000000 & 0,896418 & 0,000000 & 0,000000 & 0,103582 \\
\hline DMU 6 & 0,000000 & 0,244190 & 0,000000 & 0,000000 & 0,000000 & 0,000000 & 0,000000 & 0,755810 \\
\hline
\end{tabular}




\begin{tabular}{|l|c|c|c|c|c|c|c|c|}
\hline \multicolumn{1}{|c|}{ DMU } & DMU 1 & DMU 2 & DMU 3 & DMU 8 & DMU 14 & DMU 17 & DMU 18 & DMU 21 \\
\hline DMU 7 & 0,000000 & 0,000000 & 0,000000 & 1,000000 & 0,000000 & 0,000000 & 0,000000 & 0,000000 \\
\hline DMU 8 & 0,000000 & 0,000000 & 0,000000 & 1,000000 & 0,000000 & 0,000000 & 0,000000 & 0,000000 \\
\hline DMU 9 & 0,000000 & 0,000000 & 0,000000 & 0,381048 & 0,000000 & 0,000000 & 0,000000 & 0,618952 \\
\hline DMU 10 & 0,000000 & 0,351227 & 0,000000 & 0,000000 & 0,000000 & 0,000000 & 0,000000 & 0,648773 \\
\hline DMU 11 & 0,842156 & 0,143559 & 0,000000 & 0,000000 & 0,000000 & 0,000000 & 0,000000 & 0,014284 \\
\hline DMU 12 & 0,000000 & 0,038674 & 0,013886 & 0,000000 & 0,000000 & 0,000000 & 0,000000 & 0,947440 \\
\hline DMU 13 & 0,000000 & 0,000000 & 0,000000 & 0,000000 & 0,070931 & 0,000000 & 0,000000 & 0,929069 \\
\hline DMU 14 & 0,000000 & 0,000000 & 0,000000 & 0,000000 & 1,000000 & 0,000000 & 0,000000 & 0,000000 \\
\hline DMU 15 & 0,000000 & 0,000000 & 0,000000 & 0,000000 & 0,100696 & 0,000000 & 0,000000 & 0,899304 \\
\hline DMU 16 & 0,000000 & 0,000000 & 0,000000 & 0,015998 & 0,000000 & 0,000000 & 0,000000 & 0,984002 \\
\hline DMU 17 & 0,000000 & 0,000000 & 0,000000 & 0,000000 & 0,000000 & 1,000000 & 0,000000 & 0,000000 \\
\hline DMU 18 & 0,000000 & 0,000000 & 0,000000 & 0,000000 & 0,000000 & 0,000000 & 1,000000 & 0,000000 \\
\hline DMU 19 & 0,000000 & 0,000000 & 0,000000 & 0,000000 & 0,142063 & 0,000000 & 0,000000 & 0,857937 \\
\hline DMU 20 & 0,000000 & 0,000000 & 0,000000 & 0,001001 & 0,000000 & 0,000000 & 0,000000 & 0,998999 \\
\hline DMU 21 & 0,000000 & 0,000000 & 0,000000 & 0,000000 & 0,000000 & 0,000000 & 0,000000 & 1,000000 \\
\hline
\end{tabular}

Fonte: Elaboração Própria

\subsection{Análise par-a-par - resíduo e carga movimentada}

Ao avaliar os terminais considerando apenas duas variáveis nas análises, a fronteira de eficiência muda consideravelmente. $\mathrm{Na}$ análise das variáveis quanto ao resíduo e carga movimentada, as DMU's eficientes foram os terminais Apm Terminals Itajaí SA (porto de Itajai DMU 8) e a Amazon Agency Ltda (porto de Vila do Conde - DMU 21). Entre estes dois terminais, a que se manteve mais distante da fronteira de ineficiência foi a DMU 8, muito diferente da DMU 21 que se encontra tanto na fronteira eficiente quanto na ineficiente, logo, uma falsa-positiva (Tabela 5).

Tabela 5- Resultados das eficiências padrão, invertida, composta e composta normalizada na avaliação considerando as variáveis resíduo e da carga movimentada.

\begin{tabular}{|l|l|c|c|c|c|c|}
\hline \multicolumn{1}{|c|}{ Porto } & \multicolumn{1}{|c|}{ Terminal } & DMU & Padrão & Invertida & Composta & Composta* \\
\hline Rio de Janeiro & Libra Terminais SA & 1 & 0,47919 & 1,00000 & 0,23959 & 0,25886 \\
\hline Rio de Janeiro & $\begin{array}{l}\text { Multi-Rio Operações } \\
\text { Portuárias SA }\end{array}$ & 2 & 0,82944 & 1,00000 & 0,41472 & 0,44808 \\
\hline Itaguaí & Sepetiba Tecont SA & 3 & 0,93321 & 0,49407 & 0,71957 & 0,77745 \\
\hline Natal & Seamaster Ltda & 4 & 0,00069 & 1,00000 & 0,00035 & 0,00037 \\
\hline Belém & $\begin{array}{l}\text { Cma Cgm Do Brasil Agencia } \\
\text { Maritima Ltda }\end{array}$ & 5 & 0,00184 & 0,80365 & 0,09910 & 0,10707 \\
\hline Vitória & Autoridade Portuária & 6 & 0,00105 & 0,72526 & 0,13790 & 0,14899 \\
\hline $\begin{array}{l}\text { São Francisco } \\
\text { do Sul }\end{array}$ & $\begin{array}{l}\text { Tesc - Terminal Santa Catarina } \\
\text { SA }\end{array}$ & 7 & 0,61102 & 0,36085 & 0,62509 & 0,67536 \\
\hline Itajaí & Apm Terminals Itajaí SA & 8 & 1,00000 & 0,21702 & 0,89149 & 0,96319 \\
\hline Suape & Wilson Sons SA & 9 & 0,00425 & 0,24953 & 0,37736 & 0,40771 \\
\hline Paranaguá & Agencia Maritima Orion Ltda & 10 & 0,00318 & 0,21948 & 0,39185 & 0,42337 \\
\hline Rio Grande & $\begin{array}{l}\text { Sagres Agenciamento } \\
\text { Marítimo Ltda }\end{array}$ & 11 & 0,17665 & 0,13297 & 0,52184 & 0,56381 \\
\hline Paranaguá & Oceanus Agencia Maritima SA & 12 & 0,01250 & 0,06046 & 0,47602 & 0,51431 \\
\hline
\end{tabular}




\begin{tabular}{|l|l|c|c|c|c|c|}
\hline \multicolumn{1}{|c|}{ Porto } & \multicolumn{1}{|c|}{ Terminal } & DMU & Padrão & Invertida & Composta & Composta* \\
\hline Paranaguá & $\begin{array}{l}\text { Transgolf Agencia Maritima } \\
\text { Ltda }\end{array}$ & 13 & 0,01299 & 0,34385 & 0,33457 & 0,36148 \\
\hline Paranaguá & $\begin{array}{l}\text { Marcon Servicos De } \\
\text { Despachos Em Geral Ltda }\end{array}$ & 14 & 0,21342 & 0,03356 & 0,58993 & 0,63738 \\
\hline Belém & Iss Marine Service Ltda & 15 & 0,02667 & 0,61829 & 0,20419 & 0,22062 \\
\hline Vila do Conde & $\begin{array}{l}\text { B F Fortship (Pa) Agencia } \\
\text { Maritima Ltda }\end{array}$ & 16 & 0,06247 & 0,03400 & 0,51424 & 0,55560 \\
\hline Natal & $\begin{array}{l}\text { Superservice Inspeções E } \\
\text { Operações Portuárias Ltda }\end{array}$ & 17 & 0,11765 & 0,00731 & 0,55517 & 0,59983 \\
\hline Fortaleza & $\begin{array}{l}\text { Brandao Filhos Fortship Pe } \\
\text { Agencia Maritima Ltda }\end{array}$ & 18 & 0,17792 & 0,00420 & 0,58686 & 0,63406 \\
\hline Rio de Janeiro & Oceanus Agencia Maritima SA & 19 & 0,33977 & 0,00449 & 0,66764 & 0,72134 \\
\hline Fortaleza & $\begin{array}{l}\text { Tracol - Agencia Marítima } \\
\text { Transc. Ltda }\end{array}$ & 20 & 0,88846 & 0,037346 & 0,925558 & 1,00000 \\
\hline Vila do Conde & Amazon Agency Ltda & 21 & 1,00000 & 1,00000 & 0,50000 & 0,54022 \\
\hline
\end{tabular}

Fonte: Elaboração Própria

Além desses terminais é preciso observar que a DMU 20 (Tracol - Agencia Marítima Transc. Ltda - porto de Fortaleza) apresentou o maior valor para a composta. Todavia, a DMU 20 não apresentou o maior valor para a eficiência padrão $(0,884)$, nem o menor valor para a invertida $(0,037)$, e apesar disto, foi a que obteve o maior valor na composta e, consequentemente, na composta normalizada.

Isto foi possível dado o valor da eficiência invertida que foi muito baixo e ao mesmo tempo o valor da eficiência padrão foi próximo de um. Entretanto, ao considerar o conjunto, esta DMU conseguiu ao mesmo tempo, manter-se mais distante da fronteira ineficiente e mais próxima da fronteira eficiente. A DMU 18, por exemplo, foi a que apresentou o menor valor para invertida, mas sua eficiência padrão foi de 0,177 .

As DMU's que não foram eficientes nesta análise, mas foram na análise geral, apenas a DMU 3 apresentou eficiência de 0,933, as demais foram abaixo disto. As referências para as DMU's 1, 2 e 3 foi a DMU 8 (Tabela 6). A DMU 14 apresentou duas referências; a DMU 8 (0,911) e a DMU $21(0,088)$. As DMU's 17 e 18 também apresentaram duas referências cada, com a DMU 21 a principal referência $(0,960$ e 0,878 , respectivamente), conforme Tabela 6 .

Tabela 6: Benchmarks das DMU's na análise par-a-par considerando resíduo e carga geral

\begin{tabular}{|l|l|l|}
\hline \multicolumn{1}{|c|}{ DMU } & \multicolumn{1}{c|}{ DMU_8 } & \multicolumn{1}{c|}{ DMU_21 } \\
\hline DMU_1 & 1,00000 & 0,00000 \\
\hline DMU_2 & 1,00000 & 0,00000 \\
\hline DMU_3 & 1,00000 & 0,00000 \\
\hline DMU_4 & 0,04963 & 0,95037 \\
\hline DMU_5 & 0,55667 & 0,44333 \\
\hline DMU_6 & 0,04505 & 0,95495 \\
\hline DMU_7 & 1,00000 & 0,00000 \\
\hline DMU_8 & 1,00000 & 0,00000 \\
\hline DMU_9 & 0,38105 & 0,61895 \\
\hline DMU_10 & 0,05832 & 0,94168 \\
\hline
\end{tabular}

\begin{tabular}{|l|l|l|}
\hline \multicolumn{1}{|c|}{ DMU } & \multicolumn{1}{|c|}{ DMU_8 } & \multicolumn{1}{c|}{ DMU_21 } \\
\hline DMU_11 & 0,97497 & 0,02503 \\
\hline DMU_12 & 0,04538 & 0,95462 \\
\hline DMU_13 & 0,00748 & 0,99252 \\
\hline DMU_14 & 0,91101 & 0,08899 \\
\hline DMU_15 & 0,00205 & 0,99795 \\
\hline DMU_16 & 0,01600 & 0,98400 \\
\hline DMU_17 & 0,03987 & 0,96013 \\
\hline DMU_18 & 0,12135 & 0,87865 \\
\hline DMU_19 & 0,02235 & 0,97765 \\
\hline DMU_20 & 0,00100 & 0,99900 \\
\hline DMU_21 & 0,00000 & 1,00000 \\
\hline
\end{tabular}

Fonte: Elaboração Própria 


\subsection{Análise par-a-par - resíduo e atracação}

Nesta análise, os terminais eficientes foram: Multi-Rio Operações Portuárias S.A., situada no porto do Rio de Janeiro (DMU 2) e Amazon Agency Ltda, situada no porto de Vila do Conde (DMU 21).

Na DMU 2, o modelo desconsiderou da análise a variável resíduo, atribuindo pesos apenas na variável atracação, onde a maior quantidade de atracações ocorreu neste terminal. Na DMU 21, a eficiência invertida foi menor quando comparado com a DMU 2, logo, a mais eficiente. A composta foi de 0,75 , o maior valor do conjunto de DMU's. Esta DMU foi a que teve o maior valor para o inverso do resíduo, logo, como o modelo é orientado a output e o inverso do resíduo é um output desejável, sua eficiência padrão foi máxima e manteve-se distante da fronteira ineficiente, tabela 7.

Tabela 7: Resultados das eficiências padrão, invertida, composta e composta normalizada na avaliação considerando as variáveis resíduo e atracação

\begin{tabular}{|c|c|c|c|c|c|c|}
\hline Porto & Terminal/Operador Portuário & DMU & Padrão & Invertida & Composta & Composta* \\
\hline $\begin{array}{l}\text { Rio de } \\
\text { Janeiro }\end{array}$ & Libra Terminais SA & 1 & 0,71017 & 1,00000 & 0,35508 & 0,47345 \\
\hline $\begin{array}{l}\text { Rio de } \\
\text { Janeiro }\end{array}$ & Multi-Rio Operações Portuárias SA & 2 & 1,00000 & 0,88140 & 0,55930 & 0,74574 \\
\hline Itaguaí & Sepetiba Tecont SA & 3 & 0,88162 & 0,73439 & 0,57362 & 0,76482 \\
\hline Natal & Seamaster Ltda & 4 & 0,00163 & 1,00000 & 0,00082 & 0,00109 \\
\hline Belém & $\begin{array}{l}\text { Cma Cgm Do Brasil Agencia } \\
\text { Maritima Ltda }\end{array}$ & 5 & 0,00276 & 0,80412 & 0,09932 & 0,13243 \\
\hline Vitória & Autoridade Portuária & 6 & 0,00133 & 1,00000 & 0,00066 & 0,00088 \\
\hline $\begin{array}{l}\text { São } \\
\text { Francisco do } \\
\text { Sul }\end{array}$ & Tesc - Terminal Santa Catarina SA & 7 & 0,37752 & 0,48286 & 0,44733 & 0,59644 \\
\hline Itajaí & Apm Terminals Itajaí SA & 8 & 0,65637 & 0,28469 & 0,68584 & 0,91445 \\
\hline Suape & Wilson Sons AS & 9 & 0,00360 & 0,37314 & 0,31523 & 0,42031 \\
\hline Paranaguá & Agencia Maritima Orion Ltda & 10 & 0,00462 & 0,30465 & 0,34998 & 0,46664 \\
\hline Rio Grande & Sagres Agenciamento Marítimo Ltda & 11 & 0,24911 & 0,13337 & 0,55787 & 0,74383 \\
\hline Paranaguá & Oceanus Agencia Maritima SA & 12 & 0,01258 & 0,50000 & 0,25629 & 0,34172 \\
\hline Paranaguá & Transgolf Agencia Maritima Ltda & 13 & 0,01321 & 1,00000 & 0,00661 & 0,00881 \\
\hline Paranaguá & $\begin{array}{l}\text { Marcon Servicos De Despachos Em } \\
\text { Geral Ltda }\end{array}$ & 14 & 0,34095 & 0,03355 & 0,65370 & 0,87160 \\
\hline Belém & Iss Marine Service Ltda & 15 & 0,02757 & 0,33333 & 0,34712 & 0,46283 \\
\hline $\begin{array}{l}\text { Vila do } \\
\text { Conde }\end{array}$ & $\begin{array}{l}\text { B F Fortship (Pa) Agencia Maritima } \\
\text { Ltda }\end{array}$ & 16 & 0,06176 & 1,00000 & 0,03088 & 0,04117 \\
\hline Natal & $\begin{array}{l}\text { Superservice Inspeções E Operações } \\
\text { Portuárias Ltda }\end{array}$ & 17 & 0,13075 & 0,01818 & 0,55628 & 0,74171 \\
\hline Fortaleza & $\begin{array}{l}\text { Brandao Filhos Fortship Pe Agencia } \\
\text { Maritima Ltda }\end{array}$ & 18 & 0,21176 & 0,00632 & 0,60272 & 0,80363 \\
\hline $\begin{array}{l}\text { Rio de } \\
\text { Janeiro }\end{array}$ & Oceanus Agencia Maritima SA & 19 & 0,34983 & 0,01818 & 0,66582 & 0,88776 \\
\hline Fortaleza & $\begin{array}{l}\text { Tracol - Agencia Marítima Transc. } \\
\text { Ltda }\end{array}$ & 20 & 0,88757 & 1,00000 & 0,44379 & 0,59172 \\
\hline $\begin{array}{l}\text { Vila do } \\
\text { Conde }\end{array}$ & Amazon Agency Ltda & 21 & 1,00000 & 0,50000 & 0,75000 & 1,00000 \\
\hline
\end{tabular}

Fonte: Elaboração Própria 
Tabela 8: Benchmarks das DMU's na análise par-a-par considerando resíduo e atracação

\begin{tabular}{|c|c|c|c|c|c|}
\hline DMU & DMU_2 & DMU_21 & DMU & DMU_2 & DMU_21 \\
\hline DMU_1 & 0,999989 & 0,000011 & DMU_11 & 0,981094 & 0,018906 \\
\hline DMU_2 & 1,000000 & 0,000000 & DMU_12 & 0,050999 & 0,949001 \\
\hline DMU_3 & 0,999899 & 0,000101 & DMU_13 & 0,023933 & 0,976067 \\
\hline DMU_4 & 0,596991 & 0,403009 & DMU_14 & 0,943348 & 0,056652 \\
\hline DMU_5 & 0,704554 & 0,295446 & DMU_15 & 0,034690 & 0,965310 \\
\hline DMU_6 & 0,244194 & 0,755806 & DMU_16 & 0,004609 & 0,995391 \\
\hline DMU_7 & 0,997304 & 0,002697 & DMU_17 & 0,135974 & 0,864026 \\
\hline DMU_8 & 0,997392 & 0,002608 & DMU_18 & 0,261615 & 0,738385 \\
\hline DMU_9 & 0,269736 & 0,730264 & DMU_19 & 0,050413 & 0,949587 \\
\hline DMU_10 & 0,351223 & 0,648777 & DMU_20 & - & 1,000000 \\
\hline & & & DMU_21 & - & 1,000000 \\
\hline
\end{tabular}

Fonte: Elaboração Própria

Com isso, a DMU 21 foi referência para 57,14\% da amostra (12 DMU's), considerando um valor de pelo menos 0,51 no benchmark, conforme Tabela 8.

$\mathrm{Na}$ análise geral, o modelo apresentou oito DMU's na fronteira eficiente. Entretanto, nas duas análises par-a-par, o modelo apresentou apenas duas DMU's eficientes em cada uma delas. É possível notar que a DMU 21 foi a única que se encontra na fronteira eficiente nas três análises, apesar desta ser uma falso-positivo na análise considerando as variáveis de resíduos e a carga.

O motivo da mudança na fronteira eficiente nas três análises pode ser explicado a partir dos pesos atribuídos pelo modelo aos dados utilizados nas análises. As DMU's 1, 2 e 3 foram eficientes na análise geral porque o modelo atribuiu maior importância às variáveis de carga e atracação. Dentre estas três DMU's considerando as duas análises par-a-par, o modelo apresentou os piores resultados para a DMU 1, onde na análise geral, esta foi considerada uma falso-positivo.

As DMU's 14, 17 e 18 foram eficientes na análise geral e, nas análises par-a-par, os valores de suas eficiências padrão foram baixos. Os valores das eficiências invertida se alteraram pouco, mas mantendo-se ainda em patamares baixos quando comparado na análise geral. Esta mudança pode ser explicada pelo grau de importância que o modelo atribuiu nos dados das variáveis que se apresentaram nas análises par-a-par. Com isso, é possível destacar que o modelo atribuiu maior peso na variável resíduos nas análises par-a-par quando comparado com a análise geral.

\section{CONCLUSÃO}

Este trabalho analisou a eficiência na geração de resíduos nos terminais portuários que movimentaram predominante carga geral, considerando os dados da carga movimentada, atracação e na geração de resíduos. Para que isto fosse possível, o output indesejável resíduos foi convertido para um output desejável por meio de procedimento matemático devidamente fundamentado na literatura.

Por conseguinte, foi adotado o modelo DEA-BCC orientado a output, cujo resultado apresentou baixa discriminação de DMU's eficientes, sendo necessário considerar o método da fronteira invertida para contornar este percalço, permitindo, assim, aumentar a discriminação e ordenar as DMU's. Além disto, foram realizadas três análises, uma considerando as três variáveis e as demais par-a-par, tendo à variável que diz respeito à geração de resíduos nas três análises. Sendo assim, o resultado da análise geral apresentou oito terminais portuários situados na fronteira 
eficiente. Deste total, apenas o terminal Libras Terminais SA (DMU 1) apresentou características de falso-eficiente.

O resultado das análises par-a-par apresentou uma mudança significativa na composição da fronteira eficiente quando comparado com a análise geral. Em ambas as análises par-a-par, a fronteira eficiente é formada por apenas dois terminais. $\mathrm{Na}$ análise par-a-par que considera a carga movimentada, o indicador Composta Normalizada apresentou valor máximo para o terminal Tracol - Agencia Marítima Transc. Ltda (DMU 20), apesar de não se situar na fronteira eficiente. Para estes casos, os indicadores de Composta e Composta Normalizados foram desconsiderados das análises, restringindo à análise aos indicadores de eficiências padrão e invertida.

As análises dos pesos foram importantes para determinar o grau de importância dado pelo modelo a uma das variáveis. Como não houve restrição aos pesos, o modelo DEA atribuiu peso zero nas variáveis, o que não representa à realidade nas operações portuárias.

Por fim, a análise dos benchmarks apresentou a possibilidade que as DMU's ineficientes têm de assumir as características operacionais de mais de uma referência. Esta análise é melhor compreendida quando há o auxílio de programas computacionais que permitem o desenvolvimento de gráficos tridimensionais, onde é possível observar, no gráfico, a distância entre os benchmarks e as DMU's ineficiente. Para estudos futuros, sugere-se uma atualização do inventário de resíduos gerados nos terminais portuários, com o intuito de disponibilizar ao meio acadêmico de informações cada vez mais atualizadas nesta temática. Além disto, sugere-se utilizar variáveis que impactam diretamente no cotidiano operacional do gerenciamento de resíduos nos terminais portuários. Para isto, é importante utilizar técnicas que possibilitem identificar quais as variáveis que, de fato, influenciam na análise do problema em questão.

Por fim, recomenda-se utilizar algum método que determine a importância mínima de cada variável no problema. Desta forma, será possível determinar, de forma adequada, a importância de cada variável do problema, evitando que variáveis significativas sejam anuladas pelo modelo DEA. Uma das técnicas largamente empregada por pesquisadores é o emprego do julgamento de especialistas, essencial nos problemas que envolve o emprego do DEA.

\section{AGRADECIMENTOS}

Ao Conselho Nacional de Desenvolvimento Científico e Tecnológico (CNPq) pelo suporte financeiro para elaboração deste trabalho.

\section{REFERÊNCIAS}

ACOSTA, C. M. M.; DA SILVA, A. M. V. DE A.; LIMA, M. L. P. DE. Aplicação de Análise Envoltória de Dados (DEA) para medir a eficiência em portos brasileiros. Revista de Literatura de Transportes, v. 5, n. 4, p. 88-102, 2011.

ANTAQ. Manual detalhado de de instalações portuárias para recepção de residuos - IMO -. Disponível em: <http://portal.antaq.gov.br/wp-content/uploads/2016/12/Manual-detalhado-de-instalações-portuárias-para-a-recepçãode-resíduos.pdf>. Acesso em: 10 nov. 2016.

ANTAQ. Sistema de Informações Gerenciais. Disponível <http://www.antaq.gov.br/sistemas/sig/AcessoEntrada.asp?IDPerfil=23>. Acesso em: 13 maio. 2015.

ANVISA. RDC 56 - Dispõe sobre o Regulamento Técnico de Boas Práticas Sanitárias no Gerenciamento de Resíduos Sólidos nas áreas de Portos, Aeroportos, Passagens de Fronteiras e Recintos Alfandegados, 2008.

BERTOloto, R. F.; MEllo, J. C. C. B. S. DE. Eficiência de portos e terminais privados brasileiros com características distintas. Journal of Transport Literature, v. 5, n. 2, p. 421, 2011. 
BRASIL. Lei n 12.305/2010 - Política Nacional de Resíduos Sólidos - PNRS. . 2010, p. 1-22.

CHANG, Y. T. Environmental efficiency of ports: A Data Envelopment Analysis approach. Maritime Policy and Management, v. 40, n. 5, p. 467-478, 2013.

CHARNES, A.; COOPER, W. W.; RHODES, E. Measuring the efficiency of decision making units. v. 2, p. 429-444, 1978.

COOPER, W. W.; SEIFORD, L. M.; TONE, K. Introduction to Data Envelopment Analysis and its use with DEAsolver Software and references. New York: Springer Science + Business Media, Inc., 2006.

CORTEZ, L. C. S.; BOtTinO, D. B.; PASChOAlino, F. F.; MELlO, J. C. C. B. S. DE. Estudo da eficiência dos times de futebol que mais investiram em jogadores para temporada 2008-2009. Relatório de Pesquisa em Engenharia de Produção - RPEP, v. 10, n. 2, p. 1-15, 2010.

FREITAS, M. A. V. DE. Manual de boas práticas portuárias do porto do Rio de Janeiro. Rio de Janeiro: COPPE/UFRJ, 2014.

GIACOMELLO, CINTIA P.; OLIVEIRA, R. L. DE. Análise Envoltória de Dados (DEA): uma proposta para avaliação de desempenho de unidades acadêmicas de uma universidade. Revista GUAL, v. 7, n. 2, p. 130-151, 2014.

GUEDES, L. E. M.; PENA, R. C. M.; GUERREIRO, A. DOS S. Análise de Eficiência dos Terminais Portuários do Mercosul. XXII ANPET, p. 319-330, 2008.

IBAMA. Instrução normativa N 13 - Lista Brasileira de Residuos Sólidos, 2012.

ITOH, H. Efficiency Changes At Major Container Ports in Japan: a Window Application of Data Envelopment Analysis. Review of Urban \& Regional Development Studies, v. 14, n. 2, p. 133-152, 2002.

LETA, F. R.; SOARES DE MELlO, J. C. C. B.; GOMES, E. G.; ANGULO MEZA, L. Métodos de melhora de ordenação em DEA aplicados à avaliação estática de tornos mecânicos. Investigação Operacional, v. 25, n. 2, p. 229$242,2005$.

LINS, M. P. E.; MEZA, L. A. Análise Envoltória de Dados e perspectivas de integração no ambiente do Apoio à Decisão. Rio de Janeiro: COPPE/UFRJ, 2000.

MARTINEZ-BUDRÍA, E.; DIAZ-ARMAS, R.; NAVARRO-IBAÑEZ, M.; RAVELO-MESA, T. A study of the efficiency of spanish port authorities using Data Envelopment Analysis. International Journal of Transport Economics, v. 26, n. 2, p. 237-253, 1999.

MOHEE, R.; SURROOP, D.; MUDHOO, A.; RUGHOOPUTH, B. K. Inventory of waste streams in an industrial port and planning for a port waste management system as per ISO14001. Ocean and Coastal Management, v. 61, p. 1019, 2012.

MONIÉ, F.; VIDAL, S. M. D. S. C. Cidades, portos e cidades portuárias na era da integração produtiva. RAP Rio de Janeiro, v. 40, n. 6, p. 975-995, 2006.

PARK, R.-K.; DE, P. An Alternative Approach to Efficiency Measurement of Seaports. Maritime Economics \& Logistics, v. 6, p. 53-69, 2004.

PEREIRA, S. L.; FONTANA, C. M. M.; FOnTANA, C. F.; SAKURAI, C. A. Management of Port Solid Waste Framework. International Journal of Energy and Enviroment, v. 8, 2014.

RIOS, L. R.; MAÇADA, A. C. G.; BECKER, J. L. Análise da Eficiência das Operações nos Terminais de Contêineres do Mercosul. XXVIII EnANPAD, p. 1-14, 2004.

RODRIGUES, M. V. S.; AQUINO, M. D. DE; THOMAZ, A. C. F. Análise da eficiência na produção de energia eólica nos principais estados brasileiros produtores, por meio da aplicação de análise por envoltória de dados. Revista Tecnologia, v. 36, n. 1 e 2, p. 18-33, 2015.

ROLL, Y.; HAYUTH, Y. Port performance comparison applying data envelopment analysis (DEA). Maritime Policy and Management: The Flagship Journal of International Shipping and Port Research, v. 20, n. 2, p. 153-161, 1993.

ROSANO-PENA, C.; DAHER, C. E.; MEDEIROS, O. R. DE. Ecoeficiência e Impacto da Regulação Ambiental na Agropecuária Brasileira com Funções Distância Direcionais. XXXVII Encontro da ANPAD, p. 1-16, 2013.

RUBEM, A. P. DOS S.; BRANDÃO, L.; MELLO, J. C. C. B. S. DE. Avaliação de unidades portuárias brasileiras com Análise Envoltória de Dados e Método de Copeland. ANPET - Congresso de Ensino e Pesquisa em Transportes, p. 


\section{$12,2014$.}

SANTOS, A. B.; SPROESSER, R. L. Caracterização e avaliação da eficiência dos terminais intermodais brasileiros. Gestão \& Regionalidade, v. 29, n. 87, p. 47-63, 2013.

SEP E UFRJ. Relatório Diagnóstico: Programa de Conformidade do Gerenciamento de Resíduos Sólidos e Efluentes Líquidos nos Portos Marítmos Brasileiros - Porto de Itaguaí. Rio de Janeiro: COPPE/UFRJ, 2014.

SOUSA JÚNIOR, J. N. C. DE. Avaliação da eficiência dos portos utilizando Análise Envoltória de Dados: Estudo de caso dos portos da região nordeste do Brasil. Fortaleza: Universidade Federal do Ceará, 2010.

TISCOSKI, J. DA S. Análise da eficiência operacional portuária, por meio da Análise Envoltória de Dados: um estudo de caso dos complexos portuários públicos movimentadores de granéis sólidos agrícolas. Florianópolis: Universidade Federal de Santa Catarina, 2016.

TONGZON, J. Efficiency measurement of selected Australian and other international ports using Data Envelopment Analysis. Transportation Research Part A: Policy and Practice, v. 35, n. 2, p. 107-122, 2001.

TSCHAFFON, P. B.; MEZA, L. A. Um Estudo de outputs indesejáveis em DEA com aplicação no setor de distribuição de energia elétrica. XLIII Simpósio Brasileiro de Pesquisa Operacional, p. 533-544, 2011.

VALENTINE, V. F.; GRAY, R. The measurement of port efficiency using Data Envelopment Analysis. Proceedings of the 9th World Conference on Transport Research, 2001. 